\title{
Análise dialélica da produtividade e do progresso da severidade de doenças foliares em híbridos de milho em duas densidades populacionais
}

\section{Diallel analyze of yield and progress of the severity of leaf diseases in maize hybrids in two population density}

\author{
Marcos Ventura Faria ${ }^{1 *}$; Marcelo Cruz Mendes ${ }^{1}$; Evandrei Santos Rossi ${ }^{2}$; \\ Omar Possatto Junior ${ }^{2}$; Diego Ary Rizzardi ${ }^{3}$; Eliza Gralak \\ Carlos Augusto Silva; ${ }^{5}$ Cacilda Márcia Duarte Rios Faria ${ }^{1}$
}

\begin{abstract}
Resumo
Sete híbridos comerciais de milho (AS1575, 2B688, Penta, GNZ2004, AG8021, Sprint e P30F53) foram utilizados como genitores de um dialelo completo, sem os recíprocos, gerando 21 cruzamentos. Os 28 tratamentos foram avaliados em duas densidades populacionais $\left(62.500\right.$ e 90.000 plantas ha $\left.^{-1}\right)$, com o objetivo de selecionar os genitores mais promissores para a geração de populações-base para a obtenção de linhagens. Dois experimentos contíguos foram conduzidos em Guarapuava-PR, no delineamento em blocos ao acaso com três repetições. Foi estimada a capacidade geral (CGC) e específica (CEC) de combinação para produtividade de grãos e severidade de doenças avaliadas pela área abaixo da curva de progresso da ferrugem comum (Puccinia sorghi) (AACPF) e da cercosporiose (Cercospora zeae-maydis) (AACPC). Os efeitos da CGC e CEC foram significativos para a produtividade de grãos e severidade das doenças em ambas as densidades de semeadura, revelando a importância tanto dos efeitos aditivos quanto não aditivos. Houve interação CGC x densidades de semeadura significativa somente para produtividade de grãos. Os cruzamentos P30F53 x AG8021 e P30F53 x Penta apresentaram CEC negativa para AACPF e AACPC na média dos experimentos. Os híbridos GNZ 2004 e P30F53 destacaram-se apresentando CGC positiva para produtividade de grãos e negativa para a AACPF e AACPC em ambos os experimentos, portanto são recomendados para a geração de populações-base para a obtenção de linhagens adaptadas tanto a densidades populacionais convencionais, quanto a plantios mais adensados, atendendo às atuais tendências de manejo da cultura do milho.
\end{abstract}

Palavras-chave: Capacidade de combinação, Cercospora zeae-maydis, Puccinia sorghi, Zea mays

\begin{abstract}
Seven commercial maize hybrids (AS1575, 2B688, Penta, GNZ2004, AG8021, Sprint e P30F53) were intercrossed in a complete diallel, excluded reciprocal, obtaining 21 crosses. The 28 treatments were evaluated in two environments characterized by different densities $\left(62,500\right.$ and 90,000 plants ha $\left.^{-1}\right)$, with
\end{abstract}

${ }^{1}$ Eng $^{\text {os }}$ Agros, Profs. Drs., Universidade Estadual do Centro Oeste, UNICENTRO, Campus CEDETEG, Guarapuava, PR. E-mail: mfaria@unicentro.br; mcmendes@unicentro.br; cfaria@unicentro.br

${ }^{2}$ Eng $^{\text {os }}$ Agros $^{\text {os }}$ Discentes do Curso de Doutorado em Genética e Melhoramento, Universidade Estadual de Maringá, UEM, Maringá, PR. E-mail: evandreiscorpium@hotmail.com; omar.pj@hotmail.com

${ }^{3}$ Eng $^{\circ} \mathrm{Agr}^{\circ}$, Discente do Curso de Mestrado em Genética e Melhoramento, UEM, Maringá, PR. E-mail: diegoragro@hotmail.com

${ }^{4}$ Eng $^{\mathrm{O}}$ Agr $^{\mathrm{o}}$, Discente do Curso de Doutorado em Agronomia, Universidade Federal do Paraná, UFPR, Curitiba, PR. E-mail: elizagralak@yahoo.com.br

${ }^{5}$ Discente do Curso de Graduação em Agronomia, UNICENTRO, Guarapuava, PR. E-mail: gutoaugusto2@hotmail.com

* Autor para correspondência 
the aim of selecting the most promising parents for generating base population to obtain lines. Two experiments were carried out in Guarapuava-PR, at randomized block design with three replications. We estimated the general (GCA) and specific (SCA) combining abilities for yield and disease severity assessed by the area under the common rust (Puccinia sorghi) progress curve (AURPC) and the area under the leaf spot (Cercospora zeae-maydis) progress curve (AULPC). The effects of GCA and SCA were significant for grain yield and diseases severity in both densities, revealing the importance of both additive and non-additive effects. There GCA $\mathrm{x}$ densities interaction was significant only for grain yield. Crossings P30F53 x AG8021 and P30F53 x Penta had negative estimates of SCA for AURPC and AULPC on the environments average. Hybrids GNZ 2004 and P30F53 stood out showing positive GCA for grain yield and negative for AURPC and AULPC in both densities and therefore are recommended for generating base populations for obtaining lines adapted for both densities, conventional and denser plantings, given the current trends in management of maize.

Key words: Combining ability, Cercospora zeae-maydis, Puccinia sorghi, Zea mays

\section{Introdução}

O milho tem se mostrado responsivo em produtividade quando se aumenta a população de plantas, principalmente em arranjos com espaçamentos reduzidos (STRIEDER et al., 2007) e essa prática vem sendo intensificada nas regiões produtoras, contudo os diferentes híbridos respondem diferentemente às variações no arranjo e na densidade populacional de plantas (DEMETRIO et al., 2008; MENDES et al., 2011), inclusive com relação à severidade de doenças (SANGOI et. al, 2000), de forma que os trabalhos de melhoramento devem considerar essa situação.

Em programas de melhoramento do milho é comum a utilização de híbridos comerciais para a geração de populações-base que possuam variabilidade e potencial genético para a obtenção de linhagens promissoras visando a o desenvolvimento de novos híbridos (HALLAUER, 1990; TROYER, 1994). As tendências do melhoramento do milho apontam para a obtenção de genótipos que respondam a plantios mais adensados (SANGOI et al., 2000; DOURADO NETO et al., 2003), e para tanto é necessário dispor de germoplasma apropriado com aptidão para uso em menores espaçamentos e maiores populações, que possuam características agronômicas adequadas e resistência às principais doenças foliares.

As doenças fúngicas na cultura do milho têm causado danos significativos no Brasil e, entre estas, a cercosporiose causada por Cercospora zeaemaydis Tehon \& E. Y. Daniels e a ferrugem comum causada por Puccinia sorghi Schw. são responsáveis por reduções significativas no rendimento da cultura (SILVA; SCHIPANSKI, 2007; BRITO et al., 2012). $\mathrm{O}$ impacto dessas doenças na cultura se deve ao fato dos patógenos colonizarem grande parte do tecido foliar, diminuindo a área fotossintetizante, levando à senescência precoce e, consequentemente, à redução da produtividade de grãos (REIS; CASA; BRESOLIN, 2004).

O desenvolvimento de cultivares resistentes é a medida mais efetiva de controle de doenças foliares do milho e a discriminação de resistência é mais confiável quando os genótipos são avaliados com base na área abaixo da curva de progresso da doença, uma vez que inclui várias medições da severidade da doença ao longo do ciclo de produção (VIEIRA et al., 2009b).

Para balizar o processo de seleção de genitores com maior potencial no melhoramento genético e para o entendimento dos efeitos genéticos que estão evolvidos na manifestação dos caracteres é comum o emprego de cruzamentos dialélicos (CHAVES et al., 2008; BALDISSERA et al., 2012; OLIBONI et al., 2013), que podem também fornecer estimativas de parâmetros importantes para seleção de genitores em diferentes condições de manejo.

Os conceitos de capacidade geral de combinação (CGC) e capacidade específica de combinação 
(CEC) permitem caracterizar qualidades genéticas dos genótipos, sendo a CGC representada pelos efeitos genéticos aditivos, com elevada importância na determinação de genótipos promissores para o melhoramento dentro de uma população, e a CEC representa o desvio do comportamento que se espera em relação a CGC, ou seja, reflete a contribuição das interações de dominância e epistasia (LORENCETTI et al., 2005).

O objetivo deste trabalho foi gerar informações sobre a capacidade de combinação de sete híbridos comerciais de milho em ambientes com diferentes arranjos/densidades populacionais em Guarapuava, PR, com finalidade de selecionar os mais promissores para a geração de populações-base para obtenção de linhagens.

\section{Material e Métodos}

Sete híbridos comerciais de milho (AS1575, 2B688, Penta, GNZ2004, AG8021, Sprint e P30F53) foram utilizados como genitores de um dialelo completo e 21 genótipos foram obtidos do intercruzamento entre eles, sem os recíprocos, totalizando 28 tratamentos.

Para a avaliação do dialelo foram conduzidos dois experimentos em área contígua no campo experimental do Departamento de Agronomia da Universidade Estadual do Centro-Oeste, no campus CEDETEG, em Guarapuava-PR, com latitude de 2523'36'S, longitude de 51'27'19' W e altitude de $1.120 \mathrm{~m}$, em Latossolo bruno distroférrico típico, textura muito argilosa (EMBRAPA, 2006). Os experimentos foram conduzidos no delineamento em blocos com os tratamentos casualizados, com três repetições.

Foram conduzidos dois experimentos que diferiram quanto ao arranjo/densidade populacional. No primeiro experimento foi adotado o espaçamento de $0,40 \mathrm{~m}$ entre linhas com população equivalente a 90.000 plantas ha $^{-1}$, sendo cada parcela constituída por 4 linhas de cinco metros de comprimento totalizando $8 \mathrm{~m}^{2}$ de área útil. No segundo experimento o espaçamento entre linhas foi de $0,80 \mathrm{~m}$, com população equivalente a 62.500 plantas ha $^{-1}$ com parcelas de duas linhas de cinco metros de comprimento, com parcelas de $8 \mathrm{~m}^{2}$ de área útil. Os experimentos foram instalados em semeadura direta, realizada em 07/11/2008, em área com cobertura de aveia preta dessecada. As adubações de base e de cobertura foram iguais em ambos os experimentos. Foram aplicados $400 \mathrm{~kg} \mathrm{ha}^{-1}$ da fórmula NPK 08-2020 na base. A adubação nitrogenada de cobertura foi parcelada em duas aplicações de $150 \mathrm{~kg} \mathrm{ha}^{-1}$ de uréia cada, sendo a primeira no estádio V3 e a segunda no estádio $\mathrm{V} 6$, totalizando $135 \mathrm{~kg} \mathrm{ha}^{-1}$ de nitrogênio.

Foram realizadas cinco avaliações da severidade da ferrugem comum do milho (Puccinia sorghi) e da cercosporiose (Cercospora zeae-maydis) a partir do início do pendoamento das plantas, conforme a escala diagramática proposta por Agroceres (1996). As médias das notas de severidade de cada experimento foram utilizadas para o cálculo da área abaixo da curva do progresso da ferrugem comum (AACPF) e da área abaixo da curva do progresso da cercosporiose (AACPC), conforme Campbell e Madden (1990). Foi avaliada a produtividade de grãos corrigida para $13 \%$ de umidade, após a correção do estande para o ideal, pelo método da covariância (RAMALHO; FERREIRA; OLIVEIRA, 2000).

Os dados foram submetidos às análises de variância individuais para cada experimento e após a verificação da homogeneidade das variâncias residuais pelo teste de Hartley (RAMALHO; FERREIRA; OLIVEIRA, 2000) foi realizada a análise conjunta, envolvendo os dois experimentos (densidades) e as médias foram comparadas pelo teste de Scott-Knott ao nível de 5\% de probabilidade. A partir das médias de cada característica foi realizada análise dialélica conjunta, segundo o modelo II de Griffing (CRUZ; CARNEIRO, 2003), utilizando o programa Genes (CRUZ, 2013). 


\section{Resultados e Discussão}

Houve diferença significativa entre os genótipos e entre os experimentos quanto à produtividade de grãos (Tabela 1), sendo que as médias foram significativamente mais elevadas na densidade de 90.000 plantas ha $^{-1}$. A associação entre o arranjo/ densidade de plantas e o aumento da produtividade de grãos de milho tem sido frequentemente reportada na literatura (DUVICK; CASSMAN, 1999; SANGOI et al., 2000; PEREIRA et al., 2008). Dourado Neto et al. (2003) relatam que em razão do aumento na interceptação de luz e do melhor aproveitamento da água e nutrientes disponíveis, acréscimos na produtividade podem ser obtidos pelo aumento da densidade de semeadura, associado à redução do espaçamento entre linhas.

Tabela 1. Resumo da análise de variância dialélica conjunta da produtividade de grãos, da área abaixo da curva de progresso da ferrugem comum (AACPF) e área abaixo da curva de progresso da cercosporiose (AACPC) e em duas densidades populacionais (62.500 e 90.000 plantas ha $\left.^{-1}\right)$ de sete híbridos comerciais de milho em cruzamento dialélico completo em Guarapuava-PR.

\begin{tabular}{|c|c|c|c|c|}
\hline \multirow{2}{*}{ FV } & \multirow{2}{*}{ GL } & \multicolumn{3}{|c|}{ QM } \\
\hline & & Produtividade de grãos & AACPF & AACPC \\
\hline Bloco/Experimento & 4 & 3813497,21 & 4761,56 & 11,96 \\
\hline Genótipo (G) & 27 & $5962088,55^{*}$ & $23575,28^{*}$ & $11,11^{*}$ \\
\hline $\mathrm{CGC}$ & 6 & $10188471,08^{*}$ & $48231,16^{*}$ & $24,11^{*}$ \\
\hline CEC & 21 & $4754549,40 *$ & $16530,74^{*}$ & $7,39 *$ \\
\hline Densidade (D) & 1 & $168169122,5^{*}$ & $251245,17^{*}$ & 9,26 \\
\hline Gx D & 27 & 712832,14 & 6016,25 & 1,12 \\
\hline CGC x D & 6 & $1563479,57^{*}$ & 9690,15 & 0,72 \\
\hline CEC x D & 21 & 469790,01 & 4966,56 & 1,23 \\
\hline Resíduo combinado & 106 & 698118,11 & 4766,26 & 1,12 \\
\hline \multirow[t]{2}{*}{$\mathrm{CV}(\%)$} & & 8,04 & 42,33 & 51,29 \\
\hline & \multicolumn{3}{|c|}{ Componentes quadráticos } & \\
\hline CGC (fixo) & & 162819,16 & 716,64 & 0,40 \\
\hline CEC (fixo) & & 559718,86 & 1166,36 & 0,85 \\
\hline
\end{tabular}

Fonte: Elaboração dos autores.

Não houve efeito significativo da interação 'genótipos x densidades' para a produtividade de grãos, o que indica que não houve inversão no comportamento relativo dos genitores e cruzamentos frente à variação da densidade populacional. A análise dialélica da produtividade de grãos demonstrou que tanto os efeitos da CGC quanto da CEC foram significativos, contudo os efeitos da CGC foram mais importantes nesse conjunto de genitores, julgando pelos valores dos componentes quadráticos (Tabela 1), demonstrando maior contribuição da presença de alelos de efeito aditivo..

Baixo valor das estimativas dos efeitos da CGC $\left(\hat{\mathrm{g}}_{\mathrm{i}}\right)$ indica que a média dos híbridos em que o genitor $i$ participou não diferiu muito da média geral do dialelo.
Alto valor, positivo ou negativo, revela que o genitor $i$ é melhor ou pior que os demais genitores incluídos no dialelo, com relação à média de seus híbridos (NIHEI; FERREIRA, 2012). As estimativas de $g_{i}$ com valores dentro do intervalo zero mais ou menos o desvio-padrão da estimativa de $\mathrm{g}_{\mathrm{i}}\left[\mathrm{DP}\left(\mathrm{g}_{\mathrm{i}}\right)\right]$ foram consideradas nulas, e indicam que os genitores não contribuíram significativamente para o aumento da produtividade de grãos, quando em cruzamento com os demais genitores (NIHEI; FERREIRA, 2012).

Para a produtividade de grãos, a interação CGC x densidades foi significativa (Tabela 1), dessa forma as estimativas da contribuição dos efeitos gênicos aditivos foram expressos separadamente para cada densidade populacional (Tabela 2). 
Tabela 2. Médias da produtividade de grãos (PG) e estimativas da capacidade geral de combinação (CGC) da produtividade de grãos (PG) $\left(\mathrm{kg} \mathrm{ha}^{-1}\right)$, da área abaixo da curva de progresso da ferrugem comum (AACPF) e área abaixo da curva de progresso da cercosporiose (AACPC) de sete híbridos comerciais de milho em cruzamento dialélico, em duas densidades populacionais.

\begin{tabular}{|c|c|c|c|c|c|c|}
\hline \multirow[b]{2}{*}{ Genótipo } & \multicolumn{2}{|c|}{ PG $\left(\mathrm{kg} \mathrm{ha}^{-1}\right)$} & \multicolumn{2}{|c|}{$\operatorname{CGC}(\hat{\mathrm{g}})}$. & \multicolumn{2}{|c|}{ CGC $\left(\hat{\mathrm{g}}_{\mathrm{j}}\right)$} \\
\hline & $\begin{array}{l}62.500 \\
\text { plantas ha }\end{array}$ & $\begin{array}{l}90.000 \\
\text { plantas ha }{ }^{-1}\end{array}$ & $\begin{array}{l}\text { PG } 62.500 \\
\text { plantas ha }\end{array}$ & $\begin{array}{l}\text { PG } 90.000 \\
\text { plantas ha }^{-1}\end{array}$ & $\mathrm{AACPF}$ & AACPC \\
\hline AS 1575 & $9.136 \mathrm{aB}^{1}$ & $11.036 \mathrm{cA}$ & $-168,93$ & $-457,78$ & $-36,42$ & $-0,35$ \\
\hline 2B688 & $10.613 \mathrm{aB}$ & $13.126 \mathrm{aA}$ & 588,95 & 539,68 & 56,13 & $-0,61$ \\
\hline Penta & $10.568 \mathrm{aB}$ & $13.725 \mathrm{aA}$ & $-125,01$ & 348,68 & 20,69 & 0,42 \\
\hline GNZ2004 & $9.385 \mathrm{aB}$ & $11.743 \mathrm{bA}$ & 214,28 & 357,20 & $-10,66$ & $-0,45$ \\
\hline AG 8021 & $9.060 \mathrm{bB}$ & $10.527 \mathrm{cA}$ & $-86,89$ & $-644,78$ & $-4,44$ & 0,35 \\
\hline Sprint & $8.322 \mathrm{cB}$ & $9.874 \mathrm{dA}$ & $-642,44$ & $-586,24$ & $-12,91$ & 1,18 \\
\hline P30F53 & $10.536 \mathrm{aB}$ & $13.227 \mathrm{aA}$ & 220,04 & 443,23 & $-12,36$ & $-0,55$ \\
\hline $\mathrm{DP}\left(\hat{\mathrm{g}}_{\mathrm{i}}\right)$ & & & 294,51 & 215,03 & 21,30 & 0,32 \\
\hline$D P\left(\hat{g}_{i}-\hat{g}_{j}\right)$ & & & 449,88 & 328,45 & 32,54 & 0,49 \\
\hline
\end{tabular}

${ }^{1}$ Médias seguidas de letras iguais pertencem a um mesmo grupo pelo teste de Scott-Knott $(\mathrm{P}<0,05)$.

Fonte: Elaboração dos autores.

Os híbridos genitores 2B688, Penta e P30F53 foram classificados no grupo dos mais produtivos em ambos os experimentos (Tabela 2). Quanto aos efeitos da CGC, o híbrido 2B688 contribuiu favoravelmente com genes de efeitos aditivos para aumento da produtividade nas duas densidades, com estimativas de $\hat{\mathrm{g}}_{\mathrm{i}}$ maiores do que duas vezes o desvio-padrão de $\hat{\mathrm{g}}_{\mathrm{i}}$, porém foi desfavorável no sentido de aumentar o progresso da severidade da ferrugem comum no grupo de cruzamentos em que participou (Tabela 2). O híbrido P30F53 apresentou estimativa positiva da CGC para a produtividade de grãos na densidade de 90.000 plantas $\mathrm{ha}^{-1}$, superando duas vezes o desvio padrão de $\hat{\mathrm{g}}_{\mathrm{i}}$, e contribuiu para a redução do progresso da severidade da cercosporiose na média das densidades populacionais (Tabela 2).

O híbrido Sprint apresentou comportamento indesejável, com baixa produtividade de grãos e estimativas negativas de elevada magnitude para a CGC. Também os híbridos AS1575 e AG8021 apresentaram estimativas de CGC negativas em ambas as densidades (Tabela 2). O genitor Penta apresentou estimativa da CGC positiva na densidade de 90.000 plantas ha ${ }^{-1}$ e negativa da densidade de 62.500 plantas $\mathrm{ha}^{-1}$, demonstrando que a escolha de genitores com base em dialelos deve considerar diferentes ambientes e manejos, nesse caso diferenciados pelo arranjo/ densidade populacional.

O efeito significativo da CEC para a produtividade de grãos, com valores de elevada magnitude, tanto positivos quanto negativos (Tabela 3), evidencia a possibilidade de selecionar genitores que podem gerar boas populações para o melhoramento interpopulacional, para extração de linhagens, que ao serem cruzadas, poderão gerar híbridos com elevada heterose (OLIBONI et al., 2013). A ausência de efeito significativo da interação 'CEC x densidades` (Tabela 1), indica que o comportamento da CEC dos cruzamentos se manteve constante, independentemente da densidade. Dessa forma, foi considerada a CEC média envolvendo os dois experimentos, correspondendo às duas densidades populacionais (Tabela 3 ). 
Tabela 3. Efeito da capacidade específica de combinação (CEC) do genitor com ele mesmo $\left(\hat{\mathrm{s}}_{\mathrm{ii}}\right)$, médias da CEC $\left(\hat{\mathrm{s}}_{\mathrm{ij}}\right)$ (diagonal superior, negrito) e médias da produtividade de grãos $\left(\mathrm{kg} \mathrm{ha}^{-1}\right)$ (diagonal inferior) de sete híbridos comerciais de milho em cruzamento dialélico completo, avaliados em duas densidades populacionais em Guarapuava-PR.

\begin{tabular}{lllllllll}
\hline Genótipo & CEC $\left(\hat{\mathrm{s}}_{\mathrm{ij}}\right)$ & AS1575 & 2B688 & Penta & GNZ2004 & AG8021 & Sprint & P30F53 \\
\hline AS1575 & 576,80 & $10.086 \mathrm{c}$ & $\mathbf{3 6 4 , 8 0}$ & $\mathbf{- 1 . 1 8 6 , 0}$ & $\mathbf{6 9 8 , 2 1}$ & $\mathbf{- 6 4 3 , 1 1}$ & $\mathbf{- 4 5 3 , 6 8}$ & $\mathbf{6 6 , 1 6}$ \\
2B688 & 605,19 & $10.752 \mathrm{~b}$ & $11.870 \mathrm{a}$ & $\mathbf{- 1 8 , 6 3}$ & $\mathbf{- 2 0 0 , 9 7}$ & $\mathbf{- 3 9 6 , 2 9}$ & $\mathbf{3 7 8 , 4 3}$ & $\mathbf{- 1 . 3 3 7 , 7 2}$ \\
Penta & 1787,07 & $8.748 \mathrm{~d}$ & $10.793 \mathrm{~b}$ & $12.147 \mathrm{a}$ & $\mathbf{3 2 9 , 9 3}$ & $\mathbf{5 4 , 6 9}$ & $\mathbf{- 2 . 0 3 1 , 7 2}$ & $\mathbf{- 7 2 2 , 4 0}$ \\
GNZ2004 & $-143,76$ & $10.806 \mathrm{~b}$ & $10.785 \mathrm{~b}$ & $10.863 \mathrm{~b}$ & $10.564 \mathrm{~b}$ & $\mathbf{- 1 4 5 , 8 3}$ & $\mathbf{4 5 6 , 1 3}$ & $\mathbf{- 8 4 9 , 9 5}$ \\
AG8021 & 389,28 & $8.814 \mathrm{~d}$ & $9.938 \mathrm{c}$ & $9.937 \mathrm{c}$ & $9.910 \mathrm{c}$ & $9.793 \mathrm{c}$ & $\mathbf{4 7 1 , 1 0}$ & $\mathbf{- 1 1 9 , 1 1}$ \\
Sprint & 190,81 & $8.754 \mathrm{~d}$ & $10.464 \mathrm{~b}$ & $7.602 \mathrm{e}$ & $10.263 \mathrm{c}$ & $9.627 \mathrm{c}$ & $9.098 \mathrm{~d}$ & $\mathbf{7 9 8 , 0 9}$ \\
P30F53 & 1082,47 & $10.220 \mathrm{c}$ & $9.694 \mathrm{c}$ & $9.857 \mathrm{c}$ & $9.903 \mathrm{c}$ & $9.983 \mathrm{c}$ & $10.651 \mathrm{~b}$ & $11.882 \mathrm{a}$ \\
\hline DP $\left(\hat{\mathrm{s}}_{\mathrm{ii}}\right)=638,15$ & & & & & & & \\
DP $\left(\hat{\mathrm{s}}_{\mathrm{ij}}=749,9\right.$ & & & & & & \\
DP $\left(\hat{(}_{\mathrm{ij}} \hat{\mathrm{s}}_{\mathrm{ik}}\right)=1111,60$ & & & & & & & \\
DP $\left(\hat{\mathrm{s}}_{\mathrm{ij}} \mathrm{s}_{\mathrm{km}}\right)=1040,23$ & & & & & & & \\
\hline
\end{tabular}

${ }^{1}$ Médias seguidas de letras iguais pertencem a um mesmo grupo pelo teste de $\operatorname{Scott}-\operatorname{Knott}(\mathrm{P}<0,05)$.

$\mathrm{DP}\left(\hat{\mathrm{s}}_{\mathrm{ii}}\right)=$ desvio-padrão das estimativas da capacidade de combinação do cruzamento do genitor com ele mesmo; DP $\left(\hat{\mathrm{s}}_{\mathrm{ij}}\right)=\operatorname{desvio-padrão}$ das estimativas de capacidade específica de combinação entre genitores distintos; DP $\left(\hat{\mathrm{s}}_{\mathrm{ij}-} \hat{\mathrm{s}}_{\mathrm{ik}}\right)=$ desvio padrão do contraste da estimativa de CEC entre híbridos com um genitor em comum; DP $\left(\hat{\mathrm{s}}_{\mathrm{ij}} \hat{\mathrm{s}}_{\mathrm{km}}\right)=$ desvio padrão do contraste de estimativas de CEC entre híbridos sem genitores em comum.

Fonte: Elaboração dos autores.

O cruzamento Sprint $x$ Penta apresentou comportamento indesejável, uma vez que a estimativa da CEC para produtividade de grãos foi negativa e de elevada magnitude $(-2.031,72 \mathrm{Kg}$ ha${ }^{1}$ ), bem como apresentou a pior média entre todos os genótipos avaliados (Tabela 3), provavelmente devido ao grau de parentesco entre esses dois híbridos, os quais foram desenvolvidos pelo mesmo programa de melhoramento.

O cruzamento P30F53 x Sprint apresentou a maior estimativa positiva da CEC para produtividade de grãos na média dos experimentos (Tabela 3), porém o genitor Sprint apresentou as estimativas de CGC negativas de maior magnitude e as piores médias entre os genitores (Tabela 2), o que põe em dúvida a possibilidade de utilização desses genitores para geração de populações para fins de melhoramento interpopulacional. A elevada CEC observada é resultante da manifestação dos genes de efeitos não aditivos em cruzamentos entre indivíduos geneticamente divergentes (FUZATTO et al., 2002; OLIBONI et al., 2012).

Também foram considerados os efeitos de CEC decorrentes do cruzamento do genitor com ele mesmo $\left(\hat{\mathrm{s}}_{\mathrm{ii}}\right)$. A análise desses efeitos indica a direção dos desvios de dominância, de modo que se a estimativa for negativa os desvios de dominância serão predominantemente positivos e vice-versa (SOUZA et al., 2012). Embora o genitor GNZ2004 tenha apresentado estimativa negativa de $\hat{\mathrm{s}}_{\mathrm{ii}}$ para a produtividade de grãos (Tabela 3 ), a magnitude do valor de $\hat{s}_{\mathrm{ii}}$ foi pequena, indicando que a sua frequência gênica está mais próxima da frequência média da população e, consequentemente, menos divergente ele é em relação aos demais genitores. Assim, a heterose média manifestada nos híbridos em que o genitor GNZ2004 participa também será pequena. Os genitores Penta e P30F53 apresentaram valores absolutos de $\hat{\mathrm{s}}_{\mathrm{ii}}$ de elevada magnitude (Tabela 3) e os valores positivos de $\hat{\mathrm{s}}_{\mathrm{ii}}$ revelam que a média dos efeitos heteróticos nos cruzamentos em que participaram foi negativa.

As médias da produtividade de grãos foram classificadas em cinco grupos pelo teste de Scott Knott, e os genitores Penta, 2B688 e P30F53 foram significativamente mais produtivos que os cruzamentos (Tabela 3). Entretanto, houve cruzamentos que se classificaram no segundo grupo 
de genótipos mais produtivos (GNZ2004 x AS1575, GNZ2004 x 2B688, GNZ2004 x Penta, 2B688 x Sprint, Penta x 2B688 e P30F53 x Sprint) que não diferiram do genitor GNZ2004 e foram superiores aos genitores Sprint, AS1575, AG8021 (Tabela 3), sendo que nesses cruzamentos um dos genitores possui elevada CGC (Tabela 2).

Com relação à área abaixo da curva de progresso da ferrugem comum (AACPF) e da área abaixo da curva de progresso da cercosporiose (AACPC) foram verificadas diferenças significativas entre genótipos (Tabela 1). Houve diferenças significativas entre as densidades quanto à $\mathrm{AACPF}$, contudo a interação 'genótipos $\mathrm{x}$ densidades` foi não significativa (Tabela 1), indicando que os genitores e cruzamentos não apresentaram inversão de comportamento frente às variações do arranjo/densidade populacional. Os coeficientes de variação da AACPF (42,33\%) e AACPC (51,29\%) foram elevados, devido, principalmente, à presença de valores nulos obtidos nas primeiras avaliações das doenças, contudo demonstraram precisão experimental compatível com o tipo de variável avaliada e estão acordo com os valores apresentados por Brito et al. (2011) e Vieira et al. (2009a)

Houve efeito significativo da CGC e CEC para a AACPF e AACPC em ambas as densidades, contudo as interações entre as capacidades combinatórias e as densidades foram não significativas (Tabela 1) e, dessa forma, foram consideradas as médias das capacidades combinatórias envolvendo as duas densidades populacionais (Tabelas 4 e 5). Destacouse o híbrido AS1575, que apresentou estimativas negativas da CGC de magnitude acima do desvio padrão para a AACPF e AACPC (Tabela 2), demonstrando que contribui favoravelmente com locos que atuam no sentido de reduzir a severidade da ferrugem comum e da cercosporiose, conferindo maior resistência. Os híbridos genitores 2B688, GNZ2004 e P30F53 apresentaram estimativas da CGC favoráveis à redução da severidade da cercosporiose (Tabela 3).
A análise dialélica da AACPF e AACPC demonstrou que os efeitos da CGC foram mais importantes que a CEC nesse conjunto de genitores, julgando pelos valores dos componentes quadráticos (Tabela 1), demonstrando a importância da ação gênica aditiva no controle da ferrugem comum e da cercosporiose. Derera et al. (2008), Engelsing et al. (2011) e Brito et al. (2012) relatam predominância dos efeitos aditivos no controle da resistência à cercosporiose. Silva et al. (2001), estudando a resistência a Puccinia polysora em milho, definiram os efeitos da CGC sendo mais importante que da CEC, o que sugere que os efeitos gênicos aditivos possam ser importantes também para resistência a Puccinia sorghi.

Os cruzamentos P30F53 x AG8021 e P30F53 $x$ Penta apresentaram CEC negativa para AACPF (Tabela 4) e AACPC (Tabela 5) na média dos experimentos. A seleção baseada na CEC deve levar em conta pelo menos um dos genitores com CGC favorável para o caráter em estudo para haja êxito no melhoramento (ENGELSING et al., 2011). O genitor P30F53 apresentou CGC negativa para o progresso da severidade de ambas as doenças e positiva e significativa para produtividade na densidade de 90.000 plantas ha ${ }^{-1}$ (Tabela 2), o que é um indicativo do potencial deste genitor como contribuição gênica favorável para os programas de melhoramento na síntese de populações-base para extração de linhagens com bom rendimento de grãos e maior resistência a essas doenças. Em dialelos avaliados por PFANN et al. (2009) e OLIBONI et al. (2013) o hibrido P30F53 também fez parte dos cruzamentos mais produtivos e com capacidade combinatória favorável, indicando ser promissor para uso no melhoramento na geração de população base. 
Tabela 4. Efeito da capacidade específica de combinação (CEC) do genitor com ele mesmo $\left(\hat{\mathrm{s}}_{\mathrm{ii}}\right)$, médias da CEC $\left(\hat{\mathrm{s}}_{\mathrm{ij}}\right)$ (diagonal superior, negrito) e médias da área abaixo da curva do progresso da ferrugem comum (Puccinia sorghi) (AACPF) (diagonal e inferior) de sete híbridos comerciais em cruzamento dialélico completo em duas densidades populacionais em Guarapuava-PR.

\begin{tabular}{lllllllll}
\hline Genótipo & CEC $\left(\hat{\mathrm{s}}_{\mathrm{ij}}\right)$ & AS1575 & 2B688 & Penta & GNZ2004 & AG8021 & Sprint & P30F53 \\
\hline AS1575 & 5,51 & $94.40 \mathrm{a}$ & $\mathbf{- 2 6 , 4 1}$ & $\mathbf{- 5 2 , 8 4}$ & $\mathbf{1 , 5 1}$ & $\mathbf{3 2 , 7 7}$ & $\mathbf{1 4 , 1 5}$ & $\mathbf{1 9 , 7 8}$ \\
2B688 & 46,38 & $155,03 \mathrm{a}^{1}$ & $320.39 \mathrm{c}$ & $\mathbf{- 6 7 , 7 3}$ & $\mathbf{1 6 , 8 7}$ & $\mathbf{9 , 2 7}$ & $\mathbf{- 6 0 , 0 9}$ & $\mathbf{3 5 , 3 3}$ \\
Penta & $-6,05$ & $93,16 \mathrm{a}$ & $170,83 \mathrm{a}$ & $187.07 \mathrm{a}$ & $\mathbf{4 2 , 9 8}$ & $\mathbf{5 , 9 3}$ & $\mathbf{1 4 1 , 0 3}$ & $\mathbf{- 3 7 , 2 7}$ \\
GNZ2004 & $-4,01$ & $116,16 \mathrm{a}$ & $224,09 \mathrm{~b}$ & $214,76 \mathrm{~b}$ & $76.40 \mathrm{a}$ & $\mathbf{1 7 , 7 9}$ & $\mathbf{3 6 , 4 4}$ & $\mathbf{1 2 , 4 1}$ \\
AG8021 & $-1,95$ & $153,64 \mathrm{a}$ & $222,70 \mathrm{~b}$ & $183,92 \mathrm{a}$ & $164,42 \mathrm{a}$ & $130.89 \mathrm{a}$ & $\mathbf{- 9 , 8 2}$ & $\mathbf{- 1 2 , 0 2}$ \\
Sprint & $-4,98$ & $126,55 \mathrm{a}$ & $144,87 \mathrm{a}$ & $310,55 \mathrm{c}$ & $174,61 \mathrm{a}$ & $134,55 \mathrm{a}$ & $50.92 \mathrm{a}$ & $\mathbf{4 8 , 2 7}$ \\
P30F53 & $-3,25$ & $132,74 \mathrm{a}$ & $240,85 \mathrm{~b}$ & $132,79 \mathrm{a}$ & $151,13 \mathrm{a}$ & $132,90 \mathrm{a}$ & $184,74 \mathrm{a}$ & $103.75 \mathrm{a}$ \\
\hline DP $\left(\hat{\mathrm{s}}_{\mathrm{ij}}\right)=52,72$ & & & & & & & \\
DP $\left(\hat{\mathrm{s}}_{\mathrm{ij}}\right)=61,96$ & & & & & & & \\
DP $\left(\hat{\mathrm{s}}_{\mathrm{ij}} \hat{\mathrm{s}}_{\mathrm{ik}}\right)=91,84$ & & & & & & & \\
DP $\left(\hat{\mathrm{s}}_{\mathrm{ij}}-\mathrm{s}_{\mathrm{km}}\right)=85,94$ & & & & & & & & \\
\hline
\end{tabular}

${ }^{1}$ Médias seguidas de letras iguais pertencem a um mesmo grupo pelo teste de $\operatorname{Scott-Knott~}(\mathrm{P}<0,05)$.

$\mathrm{DP}\left(\hat{\mathrm{s}}_{\mathrm{ii}}\right)=$ desvio-padrão das estimativas da capacidade de combinação do cruzamento do genitor com ele mesmo; DP $\left(\hat{\mathrm{s}}_{\mathrm{ij}}\right)=\operatorname{desvio-}$ padrão das estimativas de capacidade específica de combinação entre genitores distintos; DP $\left(\hat{\mathrm{s}}_{\mathrm{ij}-} \hat{\mathrm{s}}_{\mathrm{ik}}\right)=$ desvio padrão do contraste da estimativa de CEC entre híbridos com um genitor em comum; DP $\left(\hat{\mathrm{s}}_{\mathrm{ij}-} \hat{\mathrm{s}}_{\mathrm{km}}\right)=$ desvio padrão do contraste de estimativas de CEC entre híbridos sem genitores em comum.

Fonte: Elaboração dos autores.

Tabela 5. Efeito da capacidade específica de combinação (CEC) do genitor com ele mesmo $\left(\hat{\mathrm{s}}_{\mathrm{ii}}\right)$, médias da CEC $\left(\hat{\mathrm{s}}_{\mathrm{ij}}\right)$ (diagonal superior, negrito) e médias da área abaixo da curva do progresso da cercosporiose (AACPC) (Cercospora zeae-maydis) (diagonal inferior) de sete híbridos comerciais em cruzamento dialélico completo em duas densidades populacionais em Guarapuava-PR.

\begin{tabular}{lllllllll}
\hline Genótipo & CEC $\left(\hat{\mathrm{s}}_{\mathrm{ij}}\right)$ & AS1575 & 2B688 & Penta & GNZ2004 & AG8021 & Sprint & P30F53 \\
\hline AS1575 & $-0,079$ & $1,27 \mathrm{a}$ & $\mathbf{0 , 3 6}$ & $\mathbf{- 0 , 0 1}$ & $\mathbf{0 , 9 1}$ & $\mathbf{- 0 , 5 9}$ & $\mathbf{- 1 , 1 7}$ & $\mathbf{0 , 6 6}$ \\
2B688 & $-0,011$ & $1,45 \mathrm{a}$ & $0,81 \mathrm{a}$ & $\mathbf{0 , 2 1}$ & $\mathbf{0 , 0 1}$ & $\mathbf{- 0 , 0 3}$ & $\mathbf{- 0 , 5 6}$ & $\mathbf{0 , 0 3}$ \\
Penta & 0,331 & $2,11 \mathrm{~b}$ & $2,09 \mathrm{~b}$ & $3,22 \mathrm{c}$ & $\mathbf{0 , 5 9}$ & $\mathbf{0 , 5 2}$ & $\mathbf{- 1 , 9 6}$ & $\mathbf{- 0 , 0 2}$ \\
GNZ2004 & 0,082 & $2,16 \mathrm{~b}$ & $1,01 \mathrm{a}$ & $2,61 \mathrm{~b}$ & $1,23 \mathrm{a}$ & $\mathbf{- 0 , 4 1}$ & $\mathbf{- 1 , 1 9}$ & $\mathbf{0 , 4 0}$ \\
AG 8021 & 0,670 & $1,46 \mathrm{a}$ & $1,76 \mathrm{a}$ & $3,35 \mathrm{c}$ & $1,54 \mathrm{a}$ & $3,42 \mathrm{c}$ & $\mathbf{0 , 4 0}$ & $\mathbf{- 1 , 2 3}$ \\
Sprint & 3,597 & $1,71 \mathrm{a}$ & $2,06 \mathrm{~b}$ & $1,69 \mathrm{a}$ & $1,59 \mathrm{a}$ & $2,35 \mathrm{~b}$ & $8,00 \mathrm{~d}$ & $\mathbf{- 1 , 0 9}$ \\
P30F53 & 0,043 & $1,81 \mathrm{a}$ & $0,93 \mathrm{a}$ & $1,91 \mathrm{a}$ & $0,98 \mathrm{a}$ & $2,26 \mathrm{~b}$ & $1,59 \mathrm{a}$ & $0,99 \mathrm{a}$ \\
\hline DP $\left(\hat{\mathrm{s}}_{\mathrm{iij}}\right)=0,801$ & & & & & & & \\
DP $\left(\hat{\mathrm{s}}_{\mathrm{ii}}\right)=0,94$ & & & & & & & \\
DP $\left(\hat{\mathrm{s}}_{\mathrm{ii-}} \hat{\mathrm{s}}_{\mathrm{ik}}\right)=1,40$ & & & & & & & \\
DP $\left(\hat{\mathrm{s}}_{\mathrm{ij}} \mathrm{s}_{\mathrm{km}}\right)=1,31$ & & & & & & & & \\
\hline
\end{tabular}

${ }^{1}$ Médias seguidas de letras iguais pertencem a um mesmo grupo pelo teste de $\operatorname{Scott}-\operatorname{Knott}(\mathrm{P}<0,05)$.

DP $\left(\hat{\mathrm{s}}_{\mathrm{ii}}\right)=$ desvio-padrão das estimativas da capacidade de combinação do cruzamento do genitor com ele mesmo; DP $\left(\hat{\mathrm{s}}_{\mathrm{ij}}\right)=\operatorname{desvio-}$ padrão das estimativas de capacidade específica de combinação entre genitores distintos; DP $\left(\hat{\mathrm{s}}_{\mathrm{ij}-} \hat{\mathrm{s}}_{\mathrm{ik}}\right)=$ desvio padrão do contraste da estimativa de CEC entre híbridos com um genitor em comum; DP $\left(\hat{\mathrm{s}}_{\mathrm{ij}-} \hat{\mathrm{s}}_{\mathrm{km}}\right)=$ desvio padrão do contraste de estimativas de CEC entre híbridos sem genitores em comum.

Fonte: Elaboração dos autores. 
Os efeitos mais favoráveis da CEC para a redução do progresso da severidade da ferrugem comum, avaliada pela AACPF, se manifestaram nos cruzamentos 2B688 x Penta e 2B688 x Sprint (Tabela 4). Quanto aos efeitos da CEC decorrentes do cruzamento do genitor 2B688 com ele mesmo $\left(\hat{\mathrm{s}}_{\mathrm{ii}}\right)$, foi verificado o valor positivo de maior magnitude para AACPF (Tabela 4), indicando que a frequência gênica desse genitor está mais distante da frequência média e mais divergente é ele em relação aos demais genitores, favorecendo a manifestação dos efeitos heteróticos no sentido de reduzir o progresso da severidade da ferrugem comum, uma vez que nesse caso os desvios de dominância são predominantemente negativos. Contudo, o genitor 2B688 apresentou estimativa da CGC desfavorável para a AACPF (tabela 2).

Para a AACPC, dos seis cruzamentos em que Sprint participou como genitor, cinco apresentaram estimativas negativas da $\operatorname{CEC}\left(\hat{\mathrm{s}}_{\mathrm{ij}}\right)$ favoráveis à redução do progresso da severidade da cercosporiose. Sprint apresentou o maior valor positivo de $\hat{\mathrm{s}}_{\mathrm{ii}}$ (Tabela 5), indicativo de que a frequência dos genes que atuam no controle da cercosporiose está mais distante da frequência média da população e, portanto, mais divergente ele é em relação aos demais genitores do dialelo. Entretanto, para a produtividade de grãos, o híbrido Sprint apresentou as estimativas de CGC negativas de maior magnitude e as piores médias entre os genitores (Tabela 2).

Ficou evidenciada a maior importância dos locos de efeitos aditivos no controle dos caracteres estudados. Nem sempre é possível selecionar genitores que contribuam simultaneamente para elevar a produtividade e para aumentar a resistência a doenças, contudo, os híbridos P30F53 e GNZ2004 apresentaram estimativas favoráveis ao aumento da produtividade de grãos e para a redução na média da severidade das doenças foliares em ambas as densidades populacionais e, portanto são recomendados para a geração de populações-base para a obtenção de linhagens adaptadas tanto a arranjos/densidades populacionais convencionais, quanto a plantios mais adensados, atendendo às atuais tendências de manejo da cultura do milho.

\section{Agradecimentos}

Ao $\mathrm{CNPq}$ e à Fundação Araucária de Apoio ao Desenvolvimento Científico e Tecnológico do Paraná.

\section{Referências}

AGROCERES. Guia agroceres de sanidade. São Paulo: Sementes Agroceres, 1996. 72 p.

BALDISSERA, J. N. C.; VALENTINI, G.; COAN, M. M. D.; ALMEIDA, C. B.; GUIDOLIN, A. F.; COIMBRA, J. F. M. Capacidade combinatória e efeito recíproco em características agronômicas do feijão. Semina: Ciências Agrárias, Londrina, v. 33, n. 2, p. 471-480, 2012.

BRITO, A. H.; DAVIDE, L. M. C.; VON PINHO, R. G.; CARVALHO, R. P.; REIS, M. C. Genetic control of resistance to gray leaf spot of maize in tropical germplasm. Crop Breeding and Applied Biotechnology, Viçosa, v. 12, n. 2, p. 145-150, 2012.

BRITO, A. H.; VON PINHO, R. G.; SANTOS, A. O.; SANTOS, S. Reação de híbridos de milho e comparação de métodos para avaliação da Cercosporiose e Mancha Branca. Tropical Plant Pathology, Brasília, v. 36, n. 1, p. 35-41, 2011.

CAMPBELL, C. L.; MADDEN, L. V. Monitoring epidemics: diseases. In: CAMPBELL, C. L.; MADDEN, L. V. Introduction to plant disease epidemiology. New York: J. Wiley, 1990. p. 107-128.

CHAVES, L. G.; MIRANDA, G. L.; SOUZA, L. V.; GOMES, O. P.; OLIVEIRA, J. S. Parental commercial maize selection for silage production. Revista Brasileira de Milho e Sorgo, Sete Lagoas, v. 7, n. 2, p. 183-194, 2008 .

CRUZ, C. D. GENES - a software package for analysis in experimental statistics and quantitative genetics. Acta Scientiarum Agronomy, Maringá, v. 35, n. 3, p. 271-276, 2013.

CRUZ, C. D.; CARNEIRO, P. C. S. Modelos biométricos aplicados ao melhoramento genético. Viçosa: UFV, 2003. v. 2, 585 p. 
DEMETRIO, C. S.; FORNASIERI FILHO, D.; CAZETTA, J. O.; CAZETTA, D. A. Desempenho de híbridos de milho submetidos a diferentes espaçamentos e densidades populacionais. Pesquisa Agropecuária Brasileira, Brasília, v. 43, n. 12, p. 1691-1697, 2008.

DERERA, J.; TONGOONA, P.; PIXLEY, K. V.; VIVEK, B.; LAING, M. D.; VAN RIJ, N. C. Gene action controlling gray leaf spot resistance in Southern African maize germplasm. Crop Science, Madison, v. 48, n. 1, p. 93-98, 2008.

DOURADO NETO, D. D.; PALHARES, M.; VIEIRA, P. A.; MANFRON, P. A.; MEDEIROS, S. L. P.; ROMANO, M. R. Efeito da população de plantas e do espaçamento sobre a produtividade de milho. Revista Brasileira de Milho e Sorgo, Sete Lagoas, v. 2, n. 3, p. 63-77, 2003.

DUVICK, D. N.; CASSMAN, K. G. Post-green revolution trends in yield potential of emperate maize in north-central United States. Crop Science, Madison, v. 39, n. 6, p. 1622-1630, 1999.

EMPRESA BRASILEIRA DE PESQUISA AGROPECUÁRIA - EMBRAPA. Centro Nacional de Pesquisa de Solos. Sistema brasileiro de classificação de solos. 2. ed. Brasília: Embrapa-SPI, 2006. 306 p.

ENGELSING, M. J.; ROZZETTO, D. S.; COIMBRA, J. L. M.; ZANIN, C. G.; GUIDOLIN, A. F. Capacidade de combinação em milho para resistência a Cercospora zeae -maydis. Revista Ciência Agronômica, Fortaleza, v. 42, n. 1, p. 232-241, 2011.

FUZATTO, S. R.; FERREIRA, D. F.; RAMALHO, M. A. P.; RIBEIRO, P. H. E. Divergência genética e sua relação com os cruzamentos dialélicos na cultura do milho. Ciência e Agrotecnologia, Lavras, v. 26, n. 1, p. 22-32, 2002.

LORENCETTI, C.; CARVALHO, F. I. F.; BENIN, G.; MARCHIORO, V. S.; OLIVEIRA, A. C.; SILVA, J. A. G.; HARTWIG, I.; SCHMIDT, D. A. M.; VALÉRIO, I. P. Capacidade combinatória e heterose em cruzamento dialélico de aveia (Avena sativa L.). Revista Brasileira de Agrociência, Pelotas, v. 11, n. 2, p. 143-148, 2005.

HALLAUER, A. R. Methods used in developing maize inbreed lines. Maydica, Bergamo, v. 35, n. 1, p. 1-16, 1990.

MENDES, M. C.; ROSSI, E. S.; FARIA, M. V.; ALBUQUERQUE, C. J. B.; ROSÁRIO, J. G. Efeitos de níveis de adubação nitrogenada e densidade de semeadura na cultura do milho no Centro-sul do Paraná. Pesquisa Aplicada \& Agrotecnologia, Guarapuava, v. 4, n. 2, p. 176-192, 2011.
NIHEI, T. H.; FERREIRA, J. M. Análise dialélica de linhagens de milho com ênfase na resistência a doenças foliares. Pesquisa Agropecuária Brasileira, Brasília, v. 47, n. 3, p. 369-377, 2012.

OLIBONI, R.; FARIA, M. V.; NEUMANN, M.; BATTISTELLI, G. M.; TEGONI, R. G.; RESENDE, J. T. V. Genetic divergence among maize hybrids and correlations with heterosis and combining ability. Acta Scientiarum Agronomy, Maringá, v. 34, n. 1, p. 37-44, 2012.

OLIBONI, R.; FARIA, M. V.; NEUMANN, M.; RESENDE, J. T. V.; BATTISTELLI, G. M.; TEGONI, R. G.; OLIBONI, D. F. Análise dialélica na avaliação do potencial de híbridos de milho para a geração de populações-base para obtenção de linhagens. Semina: Ciências Agrárias, Londrina, v. 34, n. 1, p. 7-18, 2013.

PEREIRA, F. R. S.; CRUZ, S. C. S.; ALBUQUERQUE, A. W.; SANTOS, J. R.; SILVA, E. T. Arranjo espacial de plantas de milho em sistema plantio direto. Revista Brasileira de Engenharia Agrícola e Ambiental, Campina Grande, v. 12, n. 1, p. 69-74, 2008.

PFANN, A. Z.; FARIA, M. V.; ANDRADE, A. A.; NASCIMENTO, I. R.; FARIA, C. M. D. R.; BRINGHENTTI, R. M. Capacidade combinatória entre híbridos simples de milho em dialelo circulante. Ciência Rural, Santa Maria, v. 39, n. 3, p. 635-641, 2009.

RAMALHO, M. A. P.; FERREIRA, D. F.; OLIVEIRA, A. C. Experimentação genética e melhoramento de plantas. Lavras: UFLA, 2000. $326 \mathrm{p}$.

REIS, E. M.; CASA, R. T.; BRESOLIN, A. C. R. Manual de diagnose e controle de doenças do milho. 2. ed. Lages: Graphel, 2004. 141 p.

SANGOI, L; ENDER, M.; GUIDOLIN, A. F.; BOGO, A.; KOTHEUÍS, D. M. Incidência e severidade de doenças de quatro híbridos de milho cultivados com diferentes densidades de plantas. Ciência Rural, Santa Maria, v. 30, n. 1, p. 17-21, 2000.

SILVA, O. C.; SCHIPANSKI, C. A. Manual de identificação e manejo das doenças do milho. 2. ed. Castro: Fundação ABC, 2007. 116 p.

SILVA, H. P.; BARBOSA, M. P. M.; NASS, L. L.; CAMARGO, L. E. A. Capacidade de combinação e heterose para resistência a Puccinia polysora Underw. em milho. Scientia Agricola, Piracicaba, v. 58, n. 4, p. 777-783, 2001.

SOUZA, L. M.; PATERNIANI, M. E. A. G. Z.; MELO, P. C. T.; MELO, A. M. T. Diallel cross among fresh market tomato inbreeding lines. Horticultura Brasileira, Brasília, v. 30, n. 2, p. 246-251, 2012. 
STRIEDER, M. L.; SILVA, P. R. F.; ARGENTA, G.; RAMBO, L.; SANGOI, L.; SILVA, A. A.; ENDRIGO, P. C. A resposta do milho irrigado ao espaçamento entre linhas depende do híbrido e da densidade de plantas. Ciência Rural, Santa Maria, v. 37, n. 3, p. 634-642, 2007.

TROYER, A. F. O. Breeding early corn. In.: HALLAUER, A. R. Speciality corns. Ames: CRC, 1994. p. 342-396.
VIEIRA, R. A.; RODOVALHO, M. A.; SCAPIM, C. A.; TESSMANN, D. J.; AMARAL JUNIOR, A. T.; BIGNOTTO, L. S. Desempenho agronômico de novos híbridos de milho-pipoca no Noroeste do Estado do Paraná, Brasil. Acta Scientiarum. Agronomy, Maringá, v. 31, n. 1, p. 29-36, 2009a.

VIEIRA, R. A.; TESSMANN, D. J.; SCAPIM, C. A.; HATA, F. T.; RODOVALHO, M. A.; BARRETO, R. R. Genetic resistance of new popcorn hybrids to foliar diseases. Crop Breeding and Applied Biotechnology, Viçosa, v. 9, n. 2, p. 140-146, 2009b. 
